\title{
ÍNDICES ECOLÓGICOS PARA A GESTÃO DA ARBORIZAÇÃO DE RUAS DE BOA VISTA-RR
}

\author{
ECOLOGICAL INDEXES FOR THE MANAGEMENT OF THE STREETS TREES IN \\ BOA VISTA-RR
}

\author{
Everaldo Marques de Lima Neto ${ }^{1}$, Daniela Biondi², Flávia Abreu Paiva Pinheiro ${ }^{3}$, Tiago Monteiro Condé 4 \\ Leandro Dias ${ }^{5}$, Maria da Penha Moreira Gonçalves ${ }^{6}$
}

\begin{abstract}
RESUMO
Os índices ecológicos são indicadores que podem ser uma ferramenta do manejo e plano diretor da arborização urbana. O objetivo desta pesquisa foi analisar índices de diversidade da arborização de ruas com o intuído de contribuir à gestão da floresta urbana de Boa Vista-RR. Primeiramente realizou-se o cadastro censitário da arborização de ruas e, posteriormente a análise da diversidade ecológica, utilizando os índices de Diversidade de Shannon-Weaver (H'), Diversidade Máxima (Hmáx), Diversidade Ecológica de Simpson (C), Equabilidade de Pielou (E), Coeficiente de mistura de Jentsch (QM) e Riqueza de Odum (d1). Os índices foram comparados e analisados em relação as zonas administrativas da cidade e a outras cidades brasileiras. Foram cadastrados 6.907 indivíduos nas calçadas distribuídas em 91 espécies diferentes. $\mathrm{O}$ índice de diversidade de Shannon-Weaver ( $\mathrm{H}^{\prime}$ ) obtido na Zona Leste foi de 2,79, sendo o maior entre as zonas da cidade. O índice de Diversidade Ecológica de Simpson (C) foi de 0,11 e Índice de Equabilidade de Pielou (E) foi de 0,58, para toda a cidade. O Coeficiente de Mistura (QM) foi melhor para a Zona Leste $(0,07)$. O índice de Odum variou entre 4,93 a 8,2. Conclui-se que a Zona Leste apresentou os melhores índices de diversidade. Diante dos resultados obtidos, recomenda-se o plantio de diferentes espécies nas Zonas Central e Sul da cidade.
\end{abstract}

Palavras-chave: Ecologia urbana; Floresta urbana; Riqueza de espécies; Planejamento da arborização.

\begin{abstract}
Ecological indices are indicators that can be used as a management tool and for the planning of urban trees. The objective was to analyze diversity indexes to serve as a subsidy for the management of the urban forest of Boa Vista-RR. Census of the trees of the sidewalks was carried out and, later, the ecological diversity of the trees of the streets, using Shannon-Weaver $\left(H^{\prime}\right)$, Maximum Diversity (Hmax), Simpson Ecological Diversity (C) Equation of Pielou (E), Coefficient of Jentsch (QM) and Wealth of Odum (d1). The indices were compared and analyzed in relation to the administrative areas of the city and other Brazilian cities. 6,907 individuals were registered on the sidewalks in 91 different species. The highest ShannonWeaver $\left(\mathrm{H}^{\prime}\right)$ diversity index found was 2.79 in the East Zone. Simpson's Ecological Diversity Index $(\mathrm{C})$ was 0.11 and Pielou's Equability Index (E) was 0.58 , for the entire city. The Mixing Coefficient (QM) was better for the East Zone (0.07). The Odum index varied from 4.93 to 8.2 in the studied areas. The East Zone had the best diversity rates. It is recommended to carry out plantings of different species in the Central and South Zones.
\end{abstract}

Keywords: Urban ecology; Urban forest; Species richness; Afforestation Planning.

\footnotetext{
Recebido em 17.11.2020 e aceito em 12.04.2021

${ }^{1}$ Engenheiro Florestal, Prof. Dr. da Universidade Federal Rural de Pernambuco. Recife/PE. Email: everaldo.limaneto@ufrpe.br

2 Engenheira Florestal. Profa. Dra. Universidade Federal do Paraná. Curitiba/PR. Email: danielabiondibatista@gmail.com

${ }^{3}$ Engenheira Florestal. Universidade Estadual de Roraima. Rorainópolis/RR. Email: flavia_abreu@hotmail.com

${ }^{4}$ Engenheiro Florestal, Prof. Dr. da Universidade Estadual de Roraima. Rorainópolis/RR. Email: tiagonafloresta@gmail.com

${ }^{5}$ Engenheiro Agrônomo. Doutorando em Ciências Florestais - UFRPE. Recife/PE. Email: leandro_dias1993@hotmail.com

${ }^{6}$ Engenheira Florestal, Profa. Dra. da Universidade Federal Rural de Pernambuco. Recife/PE. Email: penha.moreira@ufrpe.br
} 


\section{INTRODUÇÃO}

A gestão da floresta urbana requer a cooperação e parceria de uma variedade de organizações e indivíduos. Esta prática é a melhor maneira de gerenciar as informações sobre a floresta urbana, incluindo os diferentes critérios e processos para o planejamento, implantação, avaliação, diagnóstico, monitoramento e manutenção de árvores e seus agrupamentos. Dessa forma, será possível a conservação e preservação dos recursos florestais urbanos a fim de garantir qualidade e condições de existência de vidas futuras.

Randolph (2011) afirma que para maximizar os benefícios das árvores para a maior quantidade de pessoas, uma abrangente iniciativa de planejamento é muitas vezes necessária para melhor gerir as árvores em terras públicas e privadas.

A falta de planejamento é um problema que tem trazido custos crescentes na manutenção, reparos dos equipamentos urbanos e, até mesmo a perda do patrimônio arbóreo nas cidades (LIMA NETO et al., 2016). A partir dessas constatações faz-se necessário a realização de um programa de gestão para as árvores da cidade, em que se observe a quantidade de árvores e áreas verdes, composição por diferentes espécies, como também a saúde e necessidades de tratamentos das árvores.

Para Rabêlo et al. (2014) o conhecimento do patrimônio arbóreo da cidade e o diagnóstico da atual situação da população arbórea é essencial para planejar soluções inerentes à gestão da arborização.

De acordo com Maria, Biondi e Zamproni (2019), muitos gestores têm estudado a arborização como uma ferramenta mitigadora dos problemas causados pela urbanização, uma vez que o conhecimento específico de cada município é fundamental para um planejamento adequado em relação às espécies utilizadas, ao número de árvores e à localização no município.

Para Bobrowski e Biondi (2016) a diversificação e a uniformização da composição de espécies são dois atributos de planejamento que se busca trabalhar na arborização de ruas, a fim de se propiciar e intensificar benefícios ambientais e estéticos provenientes da presença de árvores nas calçadas.

Os índices de riqueza e diversidade são indicadores da diversidade de espécies e podem ser usados como ferramenta do manejo e do plano diretor da arborização urbana (BOBROWSKI; BIONDI, 2016). Esses autores afirmam que deve haver cuidado ao comparar os valores dos índices de diversidade, pois estes podem mascarar a presença de espécies exóticas e exóticas invasoras, o que pode não indicar boa qualidade ambiental da arborização.

No Brasil mesmo se tendo grande diversidade de espécies vegetais nativas, é comum a utilização de espécies exóticas no paisagismo. Na maioria das cidades brasileiras, por meio de 
censo ou inventário amostral, altos percentuais de espécies exóticas são encontrados, geralmente acima de 70\% (BIONDI; LIMA NETO, 2011).

Nesse sentido, a hipótese desta pesquisa foi que os índices ecológicos utilizados na avaliação das árvores de rua são indicadores para a gestão da arborização de uma cidade, contribuindo assim para intensificar o plantio de espécies promissoras no meio urbano.

Portanto, o presente trabalho objetivou analisar índices ecológicos obtidos por meio de cadastro censitário de árvores de rua para servir de subsídio ao planejamento da floresta urbana de Boa Vista-RR.

\section{MATERIAL E MÉTODOS}

\section{Localização e caracterização da área de estudo}

A pesquisa foi desenvolvida no município de Boa Vista, capital do Estado de Roraima, situado na região Norte do Brasil. Boa Vista está localizada na formação geomorfológica Boa Vista, na zona de clima equatorial com médias altas de temperatura alcançando $27,4^{\circ} \mathrm{C}$ e chuvas abundantes. A vegetação é do tipo Savana (gramíneo-lenhosa). Segundo a classificação de Köppen, Boa Vista encontra-se na zona climática tropical, sem que haja estação extremamente seca nem temperatura média mensal inferior a $18^{\circ} \mathrm{C}$, tratando-se de um clima tropical úmido do tipo "A", do subtipo Aw - clima tropical chuvoso com predomínio de savanas. A precipitação média é de $1.750 \mathrm{~mm}$ anuais (BOA VISTA, 2012).

A cidade de Boa Vista é a única capital brasileira localizada totalmente ao norte da linha do Equador. A cidade destaca-se entre as capitais da Amazônia pelo traçado urbano organizado de forma radial, planejado no período de 1944 a 1946 pelo engenheiro civil Darcy Aleixo Derenusson, lembrando um leque, em alusão às ruas de Paris, na França (BOA VISTA, 2012).

É o município mais populoso do estado de Roraima, contando com uma população estimada para 2020 de 419.652 habitantes, 97,7\% vivem na área urbana. O município possui densidade demográfica de 49,99 hab/ $\mathrm{km}^{2}$ (BOA VISTA, 2012). A divisão político-administrativa do município de Boa Vista origina 45 bairros que estão agrupados em cinco zonas administrativas: zona norte, central, leste, sul e oeste (Figura 1). 


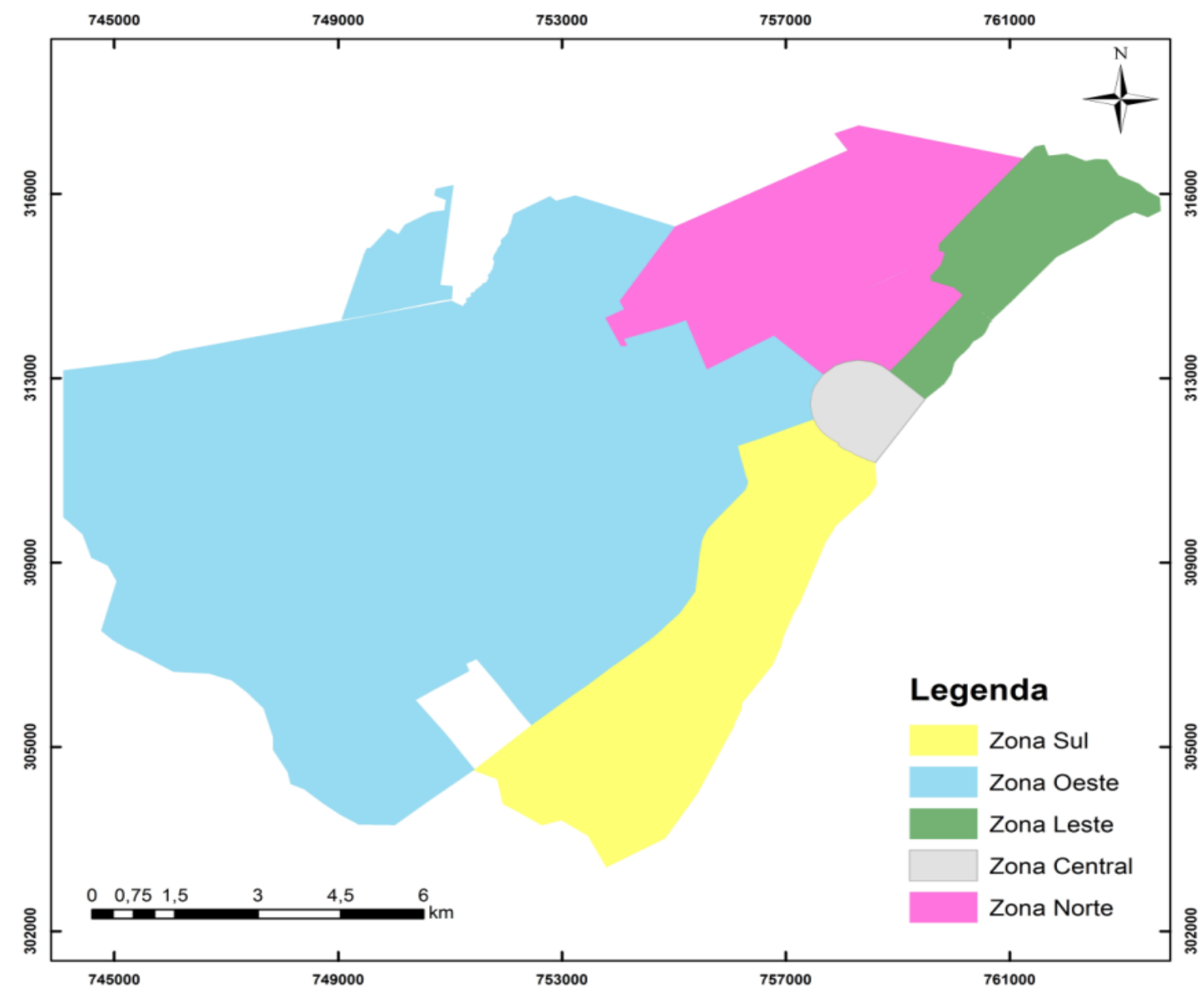

Figura 1. Distribuição das zonas administrativas de Boa Vista-RR

Figure 1. Administrative division of Boa Vista-RR

\section{Procedimentos metodológicos}

O cadastro censitário das árvores presentes nas calçadas foi realizado em 8 meses. As árvores foram cadastradas por coordenadas geográficas com uso do GPS Garmim $®$ Etrex e o nome popular da espécie identificada foi anotado em uma planilha eletrônica (POLARIS OFFICE) do Smartfone de marca SAMSUNG® GALAXY Note. Também foram contabilizadas as espécies arbustivas que nas ruas se apresentavam com porte arbóreo, ou seja, espécies com altura superior a $1,80 \mathrm{~m}$.

Concomitantemente à marcação das coordenadas geográficas foi efetuada a identificação das espécies. A identificação correspondeu ao nome científico, padronizado pela comunidade botânica e nome popular adotado pela população, o qual pode variar de uma região para outra. As espécies não identificadas foram denominadas de indeterminada, em seguida efetuado registro fotográfico e recolhido material botânico (fértil e infértil) das mesmas para posterior herborização. A identificação foi realizada no Herbário do Museu Integrado de Roraima (MIRR). 
Para análise da diversidade da arborização de ruas nas zonas administrativas da cidade de Boa Vista foram calculadas as frequências absoluta e relativa e utilizados os índices de Diversidade de Shannon-Weaver (H'), Diversidade Máxima (Hmáx), Diversidade Ecológica de Simpson (C), Equabilidade de Pielou (E), Coeficiente de mistura de Jentsch (QM) e Riqueza de Odum (d1).

O índice de Shannon-Weaver (H') é determinado com o emprego da expressão (MAGURRAN, 1988):

$$
H^{\prime}=\frac{\left[\mathrm{DT} \ln (\mathrm{DT})-\sum_{i=1}^{s} \mathrm{DA}_{i} \ln \left(\mathrm{DA}_{i}\right)\right]}{\mathrm{DT}}
$$

Em que:

$\mathrm{H}^{\prime}=$ índice de diversidade de Shannon-Weaver;

DT = densidade total;

$\mathrm{DA} \mathrm{i}=$ densidade absoluta da i-ésima espécie.

In = logaritmo neperiano.

O índice de Diversidade Ecológica de Simpson (C) é calculado com o emprego da expressão (BROWER e ZAR, 1984) :

$$
C=\frac{\left[\sum_{i=1}^{S} \mathrm{DA} i(\mathrm{DA} i-1)\right]}{[\mathrm{DT}(\mathrm{DT}-1)]}
$$

Em que:

C = Índice de Dominância de Simpson;

DT = densidade total;

$\mathrm{DAi}=$ densidade absoluta da i-ésima espécie.

Segundo Brower e Zar (1984), o índice de Equabilidade de Pielou (E) e a Diversidade Máxima (H'máx), medem a proporção da diversidade observada em relação à máxima diversidade esperada. Portanto, foram calculados com o emprego das seguintes expressões:

$$
\begin{gathered}
E=\frac{\mathrm{H}^{\prime}}{\mathrm{H}^{\prime} \operatorname{máx}} \\
H_{\text {máx }}^{\prime}=\ln (s)
\end{gathered}
$$

Em que:

$E=$ Índice de Equabilidade de Pielou;

$H^{\prime}$ = índice de Diversidade de Shannon-Weaver;

H'máx = Índice de Diversidade Máxima;

$s=$ número total de espécies amostradas;

In = logaritmo neperiano. 
Este índice é um indicador da composição florística, pois indica, em média, o número de árvores de cada espécie que pode ser encontrada no povoamento, revelando a intensidade de mistura (SOUZA; SOARES, 2013).

$$
Q M=\frac{S}{N}
$$

Em que:

$\mathrm{QM}=$ Coeficiente de Mistura;

$S$ = número total de espécies amostradas;

$\mathrm{N}=$ número total de indivíduos.

Para a análise da riqueza de espécies foi utilizado o índice de Odum, em virtude da aplicabilidade dos mesmos para o planejamento e manejo da arborização de ruas (SILVA FILHO; BORTOLETO, 2005). Esse índice é utilizado para medir a intensidade de mistura de espécies, pois é uma variação do quociente de mistura de Jentsch.

Quanto maior o valor do índice maior a diversidade. A fórmula que descreve este índice é assim representada:

$$
d 1=\frac{s}{\ln (N)}
$$

Em que:

d1 = Índice de Odum;

$\mathrm{s}=$ número total de espécies;

$\mathrm{N}=$ número total de indivíduos avaliados;

In = logaritmo neperiano.

Para a Análise de Agrupamento (AA), os dados foram analisados estatisticamente e processados na extensão (suplemento) "Action" do programa Microsoft Office Excel @

Foi utilizada a análise multivariada através da Análise de Agrupamentos (AA) para todos os índices fitossociológicos. Os índices fitossociológicos são adimensionais, como qualquer índice calculado.

O processamento da análise de agrupamento gerou um dendrograma que representou uma síntese gráfica do trabalho desenvolvido, e grande utilidade para a classificação, comparação e discussão de agrupamentos de diferenças e proximidades entre as zonas administrativas.

Com a análise de agrupamento por meio do dendrograma foram agrupadas as zonas da cidade com maior similaridade. Essa interpretação agrupa as zonas da cidade que 
apresentam maiores necessidades de atenção, no que se refere à manutenção e gestão da arborização.

\section{RESULTADOS E DISCUSSÃO}

$\mathrm{Na}$ arborização de ruas da cidade de Boa Vista, constatou-se que a composição florística é formada por 6.907 indivíduos de 91 espécies diferentes, distribuídas em 72 gêneros pertencentes a 31 famílias botânicas. Entretanto, observou-se que apenas nove espécies representam $87 \%$ do total de indivíduos utilizados na arborização (Figura 2).

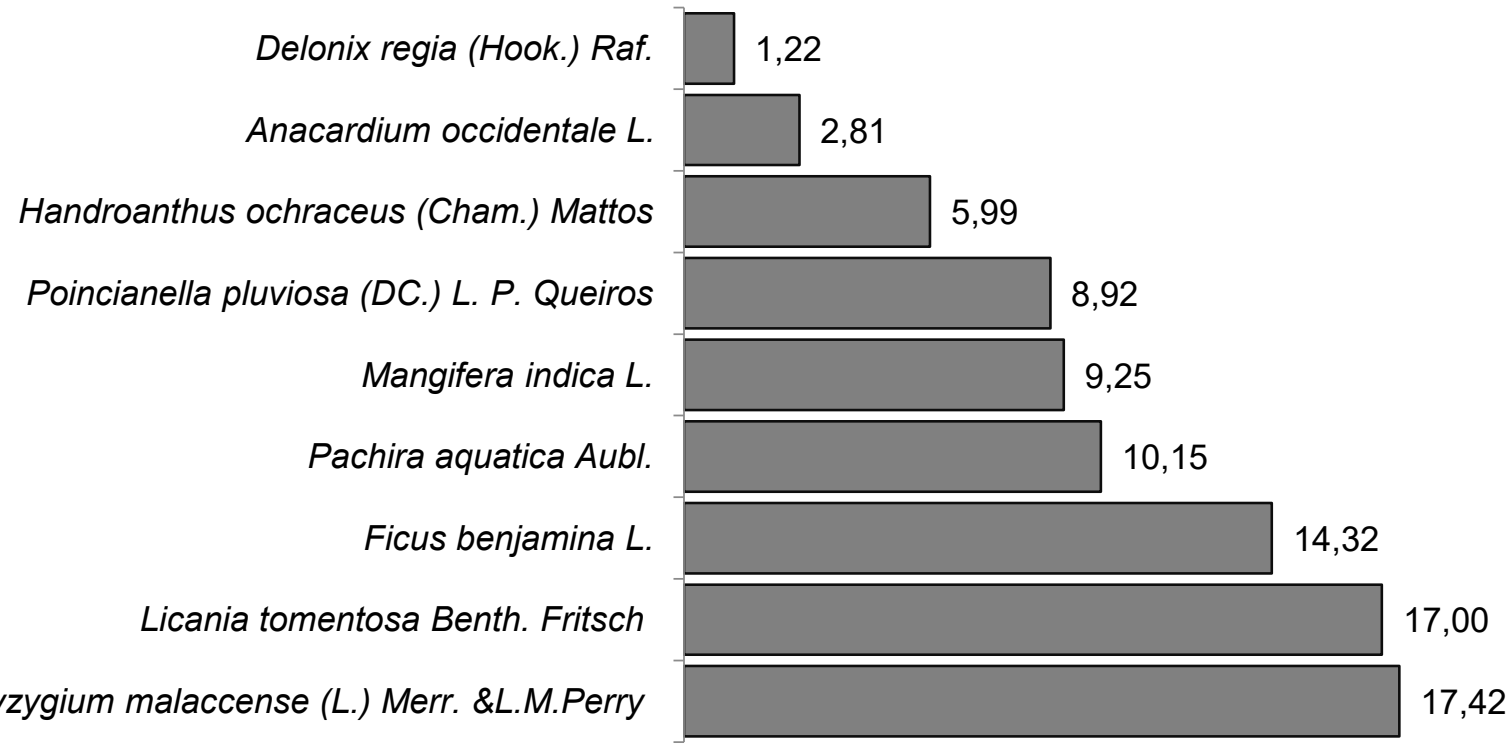

Figura 2. Espécies com mais de $1 \%$ de frequência na arborização de calçadas de Boa Vista-RR Figure 2. Species with more than $1 \%$ of frequency in the afforestation of Boa Vista-RR

Syzygium malaccense (jambo) e Licania tomentosa (oiti) estão com frequências superiores à recomendada por Milano e Dalcin (2000), os quais afirmam que a frequência por espécie deve estar entre 10 - 15\% em um bom planejamento e para o melhor desempenho de resultados ambientais satisfatórios. Os valores demonstrados não são os mais apropriados para a arborização urbana. O percentual encontrado não difere de valores encontrados para diversas cidades brasileiras de pequeno e médio porte, tais como: Aracaju-SE (LIMA NETO, MELO E SOUZA, 2011), Altamira - PA (PARRY et al., 2012) e Tuparendi - RS (MOTTER; MULLER, 2012).

O alto número de espécies e a pouca frequência, demonstram que é possível que a maioria dos plantios tenha sido feito por moradores e não pela prefeitura. Esse resultado foi 
observado por Biondi e Lima Neto (2011), em um estudo sobre as calçadas no bairro Centro de Curitiba - PR.

Cabe ressaltar que um grande número de espécies não é fator negativo para a arborização urbana, muito pelo contrário, exprime uma maior diversidade. No entanto, Lima Neto et al. (2016) ressaltam que um grande número de espécies geralmente dificulta as atividades de gestão, pois há o aumento de custos na arborização, devido à diversificação da produção de mudas e a manutenção das árvores depois de implantadas.

Quanto aos índices de diversidade aplicados observa-se os resultados por zonas administrativas da cidade (Figura 3).

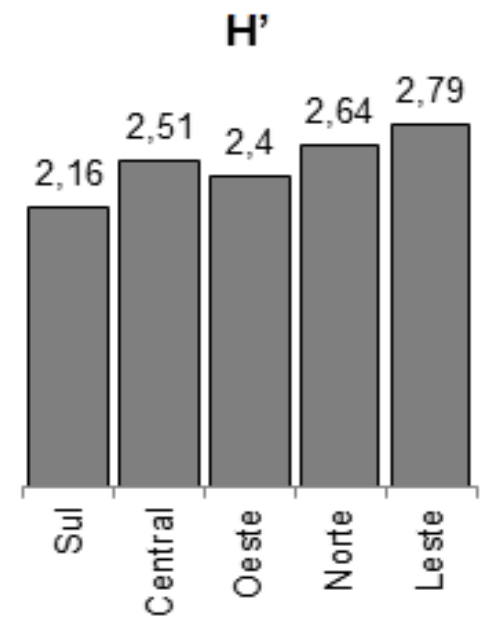

QM

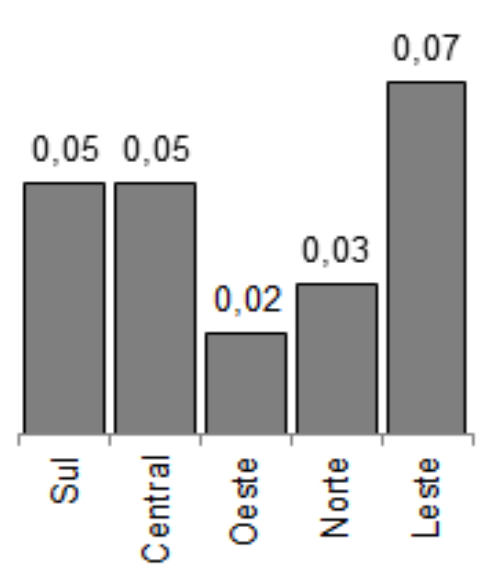

Hmáx

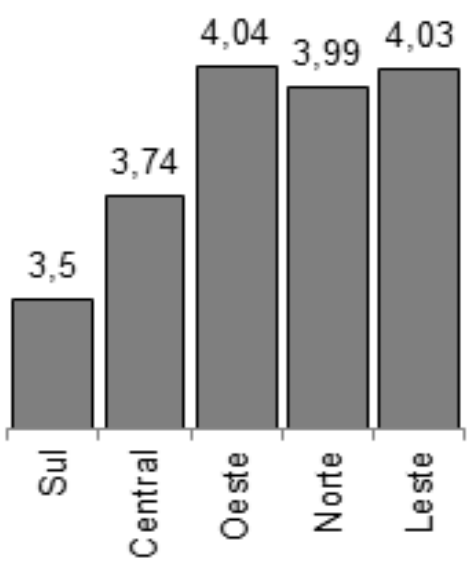

$\mathbf{E}$

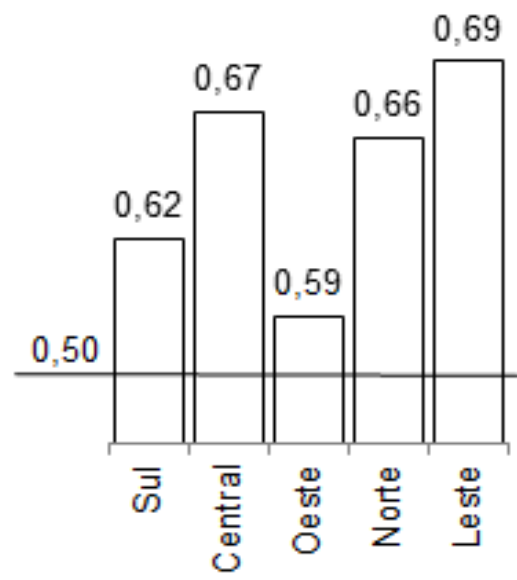

C

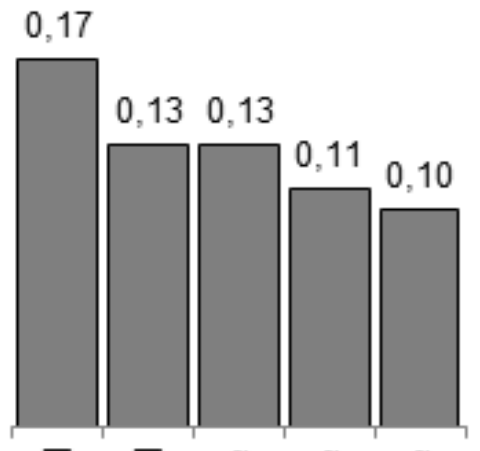

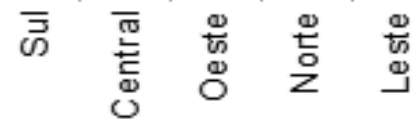

d1

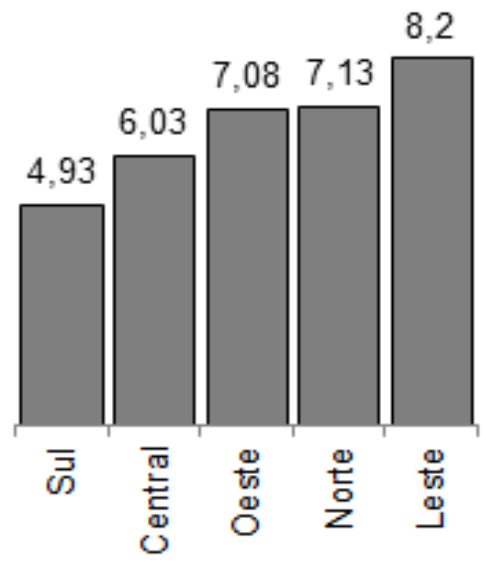

Figura 3. Índices de diversidade aplicados na arborização de calçadas de Boa Vista-RR Figure 3. Diversity indices applied to the street trees of Boa Vista -RR

O maior índice de diversidade de Shannon-Weaver $\left(H^{\prime}\right)$ encontrado foi 2,79 na Zona Leste. Este índice é superior àquele encontrado por Lima Neto et al. (2012) em uma pesquisa realizada em Rorainópolis, interior do estado de Roraima, que foi de 2,12. No entanto, este índice 
é considerado baixo se comparado ao encontrado por Silva Filho e Bortoleto (2005) que estudou a arborização viária de Estância de Águas São Pedro - SP com 3,90.

Bobrowski e Biondi (2016), ao conduzir uma pesquisa sobre a arborização de ruas de Curitiba - PR obtiveram H' com 3,24. Para esses autores, apesar da análise da diversidade de espécies ter demonstrado aumento nos valores dos índices no período de 25 anos na cidade de Curitiba, há necessidade de detalhar a composição dessa diversidade, tanto em termos quantitativos, quanto qualitativos. Para isso é necessário separar as espécies que pertencem ao ecossistema nativo da cidade, daquelas oriundas de outros ecossistemas brasileiros ou de outros países. Isto é devido ao crescente interesse da sociedade civil e dos órgãos ambientais pela valorização e manutenção da biodiversidade local.

Nesse sentido, pode-se afirmar que a arborização de ruas do município de Boa Vista apresentou diversidade menor que outras regiões brasileiras, mesmo por se tratar de uma região de savana amazônica com alta diversidade biológica. Isto pode estar associado à falta de planejamento da arborização.

O índice de Diversidade Ecológica de Simpson (C) foi de 0,11 para toda a cidade. Quanto maior este índice, menor é a diversidade. Sendo assim, a maior diversidade foi encontrada na Zona Leste com 0,10 (Figura 3). Lima Neto et al. (2012) encontraram 0,19 para a região central de Rorainópolis - RR. Este índice captura bem a distribuição de abundância de espécies, no entanto, por não apresentar um estudo específico voltado à arborização pela dificuldade de fazer comparações adequadas.

Há uma dialética entre o padrão de diversidade de espécies nas cidades, revelando a falta de consenso sobre o tema e necessidade de se chegar a um intervalo que pudesse ser considerado adequado. Visto que a alta diversidade pode ser um fator negativo do ponto de vista da gestão, e por outro lado que uma maior diversidade resulta em ganhos ambientais e melhor desempenho dos serviços ecossistêmicos da arborização.

O Índice de Pielou (E) foi de 0,58 para a cidade de Boa Vista e o melhor resultado foi encontrado na Zona Oeste $(0,59)$. Na arborização de ruas de Curitiba - PR foi encontrado 0,85 para a parcela Centro e para a cidade de Curitiba 0,67 (BOBROWSKI; BIONDI, 2016). O mesmo valor foi obtido para o bairro Centro de Rorainópolis - RR (LIMA NETO et al., 2012).

Em Itanhaém-SP, o índice relatado foi 0,71, demonstrando maior uniformidade de espécies na arborização do município (MARIA, BIONDI e ZAMPRONI, 2019). acompanhamento desse índice é importante, pois facilita a gestão das práticas silviculturais (podas e tratamentos sanitários) para cada espécie, uma vez que considera a relação da distribuição de espécies e suas dominâncias nas regiões estudadas.

Bobrowski e Biondi (2016) constataram na arborização de ruas de Curitiba - PR, que valores aproximados a 0,50 seriam mais interessantes por expressarem melhor correlação entre 
a uniformidade de indivíduos, entre as espécies presentes nas ruas e a diversidade de espécies na arborização. Os autores ressaltam que, para considerar a equidade da arborização como boa ou ruim deve-se selecionar características das ruas, bairros e da composição e distribuição das espécies em cenários, tornando a avaliação mais criteriosa.

Para Lima Neto et al. (2016), o cadastro censitário e a subdivisão da cidade em zonas administrativas permitem melhor análise da distribuição e composição de espécies da arborização de ruas de uma cidade e sua origem (nativa, exótica), podendo a partir disso propor plantios pontuais e assertivos.

A uniformidade e a diversidade são dois fatores que se buscam no planejamento, na implantação e na condução da arborização de ruas, possibilitando conciliar o melhor manejo com a melhor qualidade ambiental. Nesse sentido, os resultados do Índice de Diversidade de Simpson (C) indicaram uma uniformidade relativamente baixa de espécies, que pode ser atribuída principalmente a um grupo reduzido de espécies que ocorreram com alta densidade.

$\mathrm{Na}$ cidade de Itanhaém-SP, os índices ecológicos mostraram alta diversidade de espécies na área florestal da cidade. O índice de Pielou revelaram que a igualdade na abundância de espécies entre regiões administrativas distintas é maior do que a encontrada para o município. $O$ índice de dominância de Simpson mostrou que não há dominância de espécies em nenhuma zona administrativa ou mesmo no município.

O Coeficiente de Mistura (QM) foi melhor para a Zona Leste $(0,07)$, sendo superior ao encontrado por Brandão et al. (2010) que obtiveram 0,05 para a arborização da cidade de São João Evangelista - MG. Em estudos de florestas nativas este índice apresenta maiores valores comparados com a área urbana (SOUZA; SOARES, 2013).

O índice de Odum variou nas zonas estudadas entre 4,93 a 8,2, quanto maior o índice melhor é a diversidade. Sendo assim, o melhor resultado para este índice está na Zona Leste e o pior resultado encontra-se na Zona Sul. Isto indica uma baixa distribuição de espécies e dominância nestas Zonas.

Biz et al. (2015) encontraram no bairro Centro de Dois Vizinhos - PR um Índice de Diversidade de Odum com valor de 2,01, sendo considerado abaixo do adequado. Silva Filho e Bortoleto (2005), em um estudo na Estância de Águas de São Pedro - SP encontraram um índice de Odum de 19,50; nos setores, uma variação de 7,11 a 13,98, e nas vias públicas, uma variação de 0 a 11,55 .

Os valores encontrados para os índices anteriormente descritos foram inferiores aos observados por Bobrowski e Biondi (2014). Isto se deve ao tipo de amostragem utilizada no inventário executado e/ou na inclusão ou não de toda e qualquer espécie arbustiva encontrada.

O uso dos índices ecológicos para descrição da diversidade de espécies deve sempre ser feito mediante considerações acerca da origem das espécies florestais avaliadas, a fim de 
demonstrar a participação das espécies exóticas invasoras e de pautar ações de substituição, priorizando aquelas nativas do ecossistema local (BOBROWSKI; BIONDI, 2014).

O dendrograma obtido da análise de agrupamento (Figura 4) apresenta no eixo vertical a distância euclidiana simples, e no eixo horizontal os índices de diversidade ecológica.

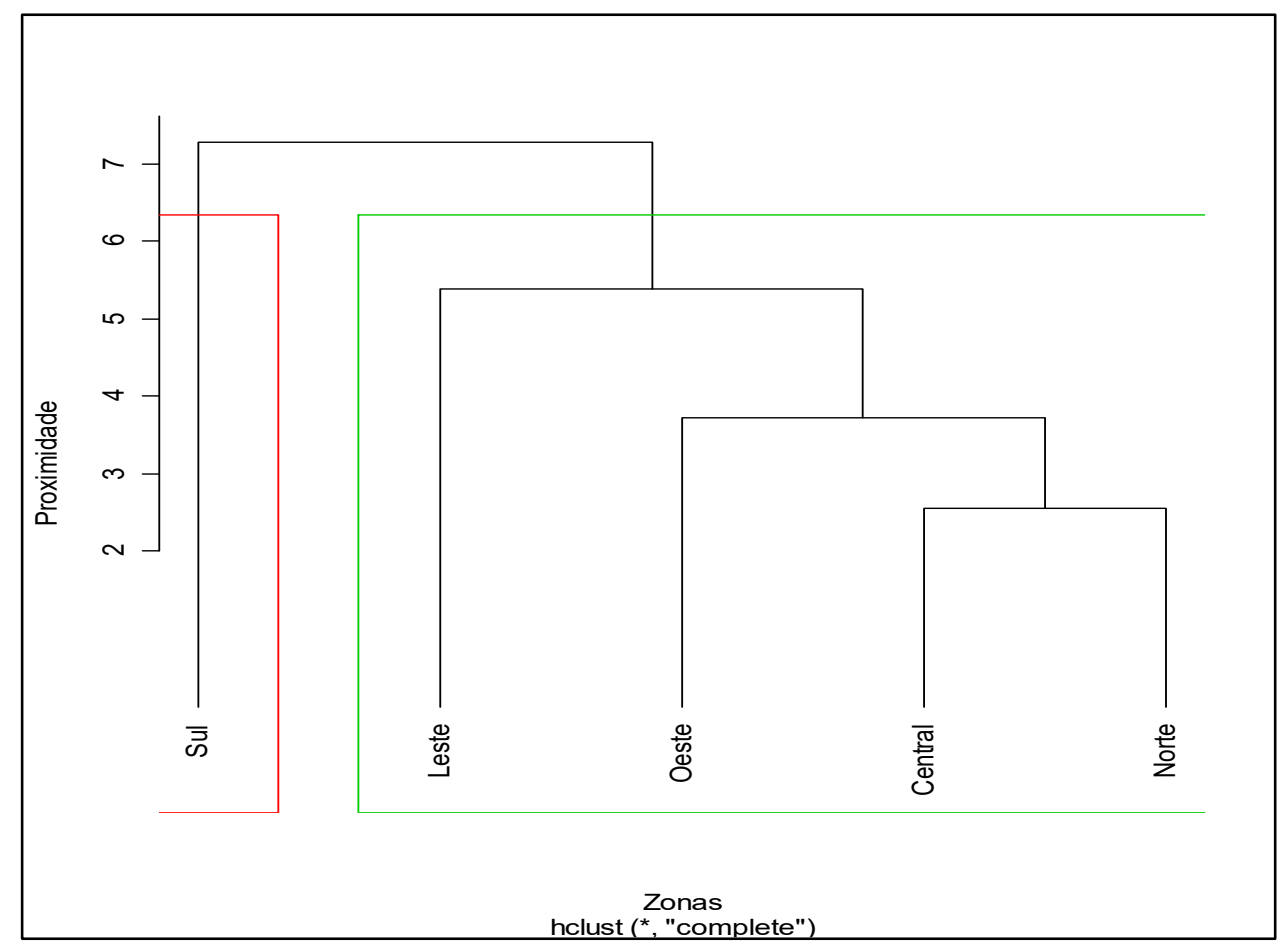

Figura 4. Dendrograma representando os índices de diversidade da arborização nas zonas administrativas de Boa Vista-RR

Figure 4. Dendrogram representing the indices of urban trees diversity in the administrative areas of Boa Vista -RR

A Figura 4 apresentou a formação de dois grandes agrupamentos, ou seja, a partir da análise de clusters pode-se observar que os índices de diversidade da Zona Sul são distintos das demais zonas, revelando baixa diversidade para a Zona Sul.

Observa-se a necessidade de intensificar plantios de diferentes espécies na Zona Sul, haja vista os menores valores dos índices de diversidade encontrados. Isto pode estar associada à ausência de critério de seleção de espécies na composição da arborização urbana do município. Nunes et al. (2013) ao estudar o bairro Ferraropólis em Garça - SP encontrou que as espécies ocorrem em uma distribuição heterogênea dos indivíduos e dominante, ou seja, existem poucas espécies com muitos indivíduos e muitas espécies com poucos indivíduos, onde deveria ter uma homogeneidade para o plantio em calçadas.

As Zonas, Leste, Oeste, Central e Norte pertencem ao mesmo agrupamento e estão com os maiores valores de índices de diversidade da cidade. Sendo assim, a intensificação de plantios deve seguir os procedimentos de espécies adaptadas às condições da cidade ou 
implantação de novas espécies. Isso acaba ocorrendo devido ao plantio aleatório de órgãos municipais ou até mesmo da população, além do plantio de espécies exóticas por ser atrativa em sua estética, ao invés de inserir espécies nativas da região (NUNES et al., 2013). Além disso, as espécies exóticas se mostram adaptadas e geralmente, com crescimento rápido e menor necessidade de manutenção nas fases iniciais de implantação.

Zamproni et al. (2019) recomendam a introdução de novas espécies a fim de diminuir a homogeneidade, de modo a contribuir para a melhoria estética e ecológica da cidade e evitar a perda do patrimônio arbóreo do município em caso de surto de praga ou doença.

\section{CONCLUSÕES}

Os índices ecológicos aplicados mostraram-se uteis para determinar homogeneidade e equilíbrio da diversidade arbórea na cidade, permitindo que seja corroborada as estratégias para a gestão da floresta urbana.

Os indicadores de diversidade, obtidos por meio de índices ecológicos, apontaram diferença entre as Zonas administrativas da cidade, a Zona Leste foi a região que apresentou o melhor comportamento dos índices de diversidade. É recomendado o plantio de outras espécies adaptadas ao ambiente urbano, a fim de equilibrar a frequência de espécies na cidade nas Zonas Central e Sul, elevando os índices de diversidade. O Quociente de Mistura foi menor na Zona Oeste, revelando a necessidade de criar padrão de arborização, como por exemplo: o plantio de uma espécie por rua ou por trechos/quadras da rua. A criação e elaboração de um padrão de plantio de espécies, sobretudo, facilitará a execução das atividades de manutenção, tais como: podas, adubação, supressão, substituição, controle fitossanitário.

É fundamental o desenvolvimento de pesquisas que impulsionem e deem subsídios a gestão da arborização de ruas, principalmente quando se trata da distribuição e escolha criteriosa de espécies, priorizando a implantação e manutenção de espécies nativas locais. 


\section{REFERÊNCIAS}

BIONDI, D.; LIMA NETO, E. M. Pesquisas em Arborização de Ruas. Curitiba: O Autor, 2011.150p.

BIZ, S.; PASTÓRIO, A. P.; BRUN, F. G. K.; BRUN, E. J.; WATZLAWICH, L. F. Indicadores de diversidade para a arborização viária do bairro Centro Norte da cidade de Dois Vizinhos Paraná. Revista da Sociedade Brasileira de Arborização Urbana, Piracicaba, v.10, n.3, p. 113, 2015.

BOA VISTA. Prefeitura Municipal. Dados Municipais. 2012. Disponível em: <http://www.boavista.rr.gov.br/mucipio/dados>. Acesso em: 09/03/2019

BOBROWSKI, R.; BIONDI, D. Comportamento de Índices de Diversidade na Composição da Arborização de Ruas. Floresta e Ambiente, Seropédica, v. 23, n. 4, p. 475-486, 2016.

BOBROWSKI, R.; BIONDI, D. Utilização de índices ecológicos para análise do tratamento paisagístico arbóreo dos parques urbanos de Curitiba-PR. Enciclopédia Biosfera, Centro Científico Conhecer, Goiânia, v.10, n.18; p. 3013, 2014.

BRANDÃO, I. M.; GOMES, L. B.; REIS, N. C. A.; FERRARO, A. C.; SILVA, A. G. ; GONÇALVES, F. G. Análise quali-quantitativa da arborização urbana do município de São João Evangelista MG. Revista da Sociedade Brasileira de Arborização Urbana, Piracicaba, v. 6, n.4, p. 158 174, 2010.

BROWER, J. E.; ZAR, J. H. Field \& laboratory methods for general ecology. 2. ed. Dubuque: Wm. C. Brown Publishers, 1984, 226 p.

LIMA NETO, E. M.; BIONDI, D.; LEAL, L.; REIS, F. L. S.; PINHEIRO, F. A. P. Análise da composição florística de Boa Vista-RR: Subsídio para a gestão da arborização de ruas. Revista da Sociedade Brasileira de Arborização Urbana, Piracicaba, v. 11, n. 1, p. 58-72, 2016.

LIMA NETO, E. M.; CONDÉ, T. M.; CRUZ, N.; COSTA, S. A.; CHAGAS, F. Índices de diversidade e equabilidade ecológica na arborização viária de Rorainópolis-RR. In: MOSTRA ACADÊMICA DO CAMPUS DE RORAINÓPOLIS, 2, 2012, Rorainópolis. Anais... Rorainópolis, 2012. Não paginado.

LIMA NETO, E. M.; MELO E SOUZA, R. Comportamento e características das espécies arbóreas nas áreas verdes públicas de Aracaju, Sergipe. Scientia Plena, Aracaju, v. 7, n. 1, p. 1- 10, 2011.

MAGURRAN, A. E. Ecological diversity and its measurement. New Jersey: Princeton University, 1988. 192 p.

MARIA, T. R. B. C.; BIONDI, D. ; ZAMPRONI, K. .Spacial indexes and biological diversity of Itanhaém, São Paulo, Brazil. Floresta , Curitiba, v. 49, n. 2, p. 267-276, 2019.

MILANO, M.S.; DALCIN, E. Arborização de vias públicas. Rio de Janeiro: Light, 2000. 206p.

MOTTER, N; MULLER, N. T. G. Diagnóstico da arborização urbana no município de TuparendiRS. Revista da Sociedade Brasileira de Arborização Urbana, Piracicaba, v. 7, n. 4, p. 27 - 36, 2012.

NUNES, R. L. ; MARMONTEL, C. V. F. ; RODRIGUES, J. P. ; MELO, A. G. C. . Levantamento quali-quantitativo da arborização urbana do bairro Ferraropólis na cidade de Garça-SP. Revista da Sociedade Brasileira de Arborização Urbana, Piracicaba, v. 8, p. 61-70, 2013. 
PARRY, M. M.; DA SILVA, M. M.; SENA, I. S.; OLIVEIRA, F. P. M. Composição florística da arborização da cidade de Altamira, Pará. Revista da Sociedade Brasileira de Arborização Urbana, Piracicaba, v. 7, n.1, p. 140 - 155, 2012.

RABÊLO, D.; SANTOS, A . F.; WANDERLEY, R. G. C.; SOUZA, P. A.; GIONGO, M. Comparação entre dois procedimentos de amostragem para inventário da arborização urbana no centro urbano de Gurupi - TO. Revista da Sociedade Brasileira de Arborização Urbana, Piracicaba, v.9, n.4, p 170-180, 2014.

RANDOLPH, J. Urban forestry. In: Environmental land use planning and management: Creating sustainable communities, watersheds, and ecosystems. Washington, DC: IslandPress, 2011. p. $328-342$.

SILVA FILHO, D.F.; BORTOLETO, S. Uso de indicadores de diversidade na definição de plano de manejo da arborização viária de Águas de São Pedro-SP. Revista Árvore, Viçosa, v. 29, n. 6, p. 973 - 982, 2005.

SOUZA, A. L.; SOARES, C. P. B. Florestas Nativas: estrutura, dinâmica e manejo. Viçosa: Editora UFV, 2013. 322 p.

ZAMPRONI, K.; BIONDI, D.; MARIA, T. R. B. C.; BOBROWSKI, R. Características fitossociológicas da arborização viária de Bonito-MS. Revista da Sociedade Brasileira de Arborização Urbana, Curitiba, v. 14, n. 4, p. 13-25, 2019. 